\title{
Der rechtwinklige Leib
}

\author{
Erhard Taverna
}

«Redlicher redet und reiner der gesunde Leib, der vollkommene und rechtwinklige: und er redet vom Sinn der Erde. - Also sprach Zarathustra.»

Hierzulande wird flächendeckend kontrolliert, in jedem grösseren Einkaufszentrum, in Fitnessanlagen, Apotheken, Praxen und Spitälern. Die wenigen Lücken füllen Gesundheitsaktionen, Tage der offenen Tür, Messestände und Brainfairs. Plakate der Lungenliga mahnen vor den Gefahren des Schnarchens, die Flyer im Tram vor verkalkten Gefässen. Kantone organisieren rauchfreie Zonen und Bündnisse gegen die Depression. Psychologische Notfallhilfe bieten die Versicherer, Diskussionsforen die Pharmaindustrie, Defibrillatoren bald jeder Verein.

Ilona Kickbusch, Professorin für Public Health, hat diese Entwicklung schon vor Jahren vorausgesehen und enthusiastisch begrüsst. Die Prophetin der WHO predigt unermüdlich den Fortschritt und die Dynamik der Gesundheitsgesellschaft als Ausdruck moderner Lebensqualität. Gesundheit sei Lebenslust und verdränge die Utopie vom perfekten Menschen der europäischen Aufklärung. Wenn 14täglich ein neues Internetportal lanciert wird, dann «tritt die Gesundheit in den Markt und wird zum Produkt». Weil die traditionelle Verwaltung der Krankenversorgung zum Nebenschauplatz gerät, so Kickbusch, wird die Wachstumsbranche Gesundheit allgegenwärtig, sie ist ein zentrales Thema von Politik, Wirtschaft und Gesellschaft. Als häufig eingeladene Referentin fordert sie eine Neudefinition des Wohlfahrtsstaates, denn nur eine massive Investition in die Gesundheit könne das marode Krankheitssystem vor dem finanziellen Kollaps bewahren. Gesundheit sei Emanzipation (Empowerment), mache Spass (Salutogenese), kenne keine Tabus (Sex, Krebs, Behinderung) und schaffe Identität und Solidarität (Selbsthilfegruppen, Coming-out von Prominenten). Neue staatliche Institutionen und private Unternehmen ergänzen sich, sie sollen mit ihren Angeboten die Gesundheitsrevolution des 21. Jahrhunderts vorantreiben, mit Verboten, Kampagnen und Kontrollen, Prävention, Fair Trade und neuen Produkten unser Verhalten verändern. Was dem «Siècle des Lumières» die Vernunft war, entwickelt sich zur aufklärerischen Vision eines globalen Lifestyle, einer alle menschlichen Bereiche umfassenden Bewegung im Namen der «neuen Gesundheit».

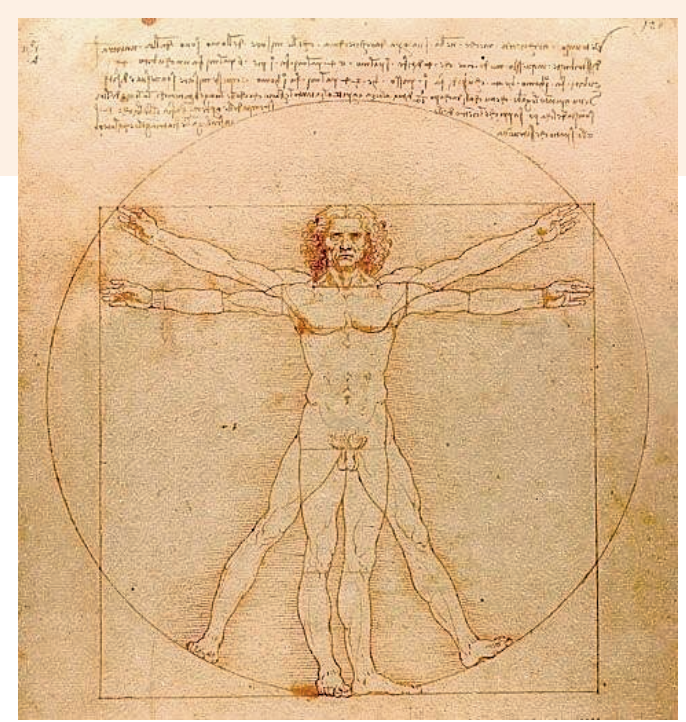

Die Etiketten wechseln, die utopischen Heilsversprechen bleiben seit der Antike und Renaissance die gleichen. Mit Friedrich Nietzsches (1844-1900) Vorstellungen vom «Sinn der Erde» begründeten alle Naturaktivisten ihre Reformen des 19. und beginnenden 20. Jahrhunderts. Von der grossen Gesundheit ist in seinem Buch der fröhlichen Wissenschaft wiederholt die Rede: «Wir Neuen, Namenlosen, Schlechtverständlichen, wir Frühgeburten einer noch unbewiesenen Zukunft - wir bedürfen zu einem neuen Zwecke auch eines neuen Mittels, nämlich einer neuen Gesundheit, einer stärkeren gewitzteren zäheren verwegeneren lustigeren, als alle Gesundheiten bisher waren.» Der Lohn dafür ist unermesslich: «ein noch unentdecktes Land, dessen Grenzen noch Niemand abgesehen hat, ein Jenseits aller bisherigen Länder und Winkel des Ideals, eine Welt so überreich an Schönem, Fremdem, Fragwürdigem, Furchtbarem und Göttlichem, dass unsere Neugierde ebensowohl wie unser Besitzdurst ausser sich geraten sind.»

Die statistische Lebensdauer hat sich seit Nietzsches Tod verdoppelt, viele Krankheiten sind besiegt, die Folgen davon sind aber auch bisher unbekannte, gravierende Probleme. Unzählige Kriege und einige Technologien weiter, stellt sich eine privilegierte Minderheit erneut die Frage nach der Machbarkeit dieser grossen Gesundheit. Kann dieser unzuverlässige Leib mit lückenloser Prävention, mit «human enhancement» und Gentechnik gebändigt werden, und wären die Besitzer besser, gerechter und umweltverträglicher? Kaum ein Philosoph der Neuzeit hat so viel über Krankheit und Gesundheit nachgedacht wie der einsame Wanderer am Silsersee: «Denn eine Gesundheit an sich gibt es nicht [...]. Zuletzt bliebe noch die grosse Frage offen, ob wir 
der Erkrankung entbehren könnten, selbst zur Entwicklung unserer Tugend, und ob nicht namentlich unser Durst nach Erkenntnis und Selbsterkenntnis der kranken Seele so gut bedürfe als der gesunden: kurz, ob nicht der alleinige Wille zur Gesundheit ein Vorurteil, eine Feigheit und vielleicht ein Stück feinster Barbarei und Rückständigkeit sei.» In jeder Utopie ist die Freiheit der Preis des Menschen für das kollektive Glück. Die totale Gesundheit ist etwas für Übermenschen oder solche, die sich dafür halten. In unseren Tagen ist es die Schriftstellerin und Juristin Juli Zeh (geboren 1974), die mit dem Theaterstück «Corpus Delicti» erneut ihr gutes Gespür für politisch brisante Themen beweist. In einem Gerichtsverfahren der Zukunft wird die Angeklagte zur Märtyrerin der Widerstandsgruppe R.A.K., Recht auf Krankheit. Der Verteidiger hat wie die Hauptfigur einen Makel, er liebt eine Frau mit dem falschen Immunsystem, was natürlich verboten ist. Die Autorin, die den deutschen Sicherheitsminister wegen der Einführung eines Passes mit biometrischen Daten verklagt hat, will der blinden Gegenwart mit einem vorgezogenen Rückblick auf die heutige Zeit zu einer Vogelperspektive verhelfen. In ihren eigenen Worten: «Ich entziehe einer Instanz das Vertrauen, die lieber der DNS eines Menschen als seinen Worten glaubt. Ich entziehe einem Recht das Vertrauen, das seine Erfolge einer vollständigen Kontrolle verdankt. Ich entziehe einem Volk das Vertrauen, das glaubt, totale Durchleuchtung schade nur dem, der etwas zu verbergen hat.» Wo lebt dieses Volk? Vielleicht dort, wo alle überwacht und überversichert, mit Schutzmasken, Kaliumjodidtabletten und Tamiflu auf ihren Bunkern leben, das eigene Wohlfühlglück selbstgefällig über alles stellen und dabei vor lauter Gesundheitskontrollen immer kränker werden?

- Kickbusch I. Die Gesundheitsgesellschaft. Gamburg: Verlag für Gesundheitsförderung; 2006.

- Nietzsche F. Die fröhliche Wissenschaft; Also sprach Zarathustra. Stuttgart: Alfred Kröner; 990.
David Künzler, Hausen am Albis

\author{
Ungeheuer I \\ UNGEHEUER \\ im Meer \\ voll Öl \\ für unsere \\ UNGEHEUER \\ viel Energie \\ verbrauchenden \\ Motor- \\ UNGEHEUER \\ und unsern \\ UNGEHEUER \\ grossen \\ Wärmebedarf \\ und wenn dem \\ UNGEHEUER \\ der Fuss bricht und \\ UNGEHEUER \\ viel Öl ins Meer dringt \\ wer reinigt die \\ UNGEHEUER \\ grosse Meeres- \\ verschmutzung \\ das Öl- \\ UNGEHEUER \\ injiziert ins Meer \\ macht dann \\ viel Leben zunichte \\ UNGEHEUER \\ -lich
}

\section{Ungeheuer II}

(ungeheure Ölplattform in der Nordsee)

Menschenwerk Meeresungeheuer

einem Saurier gleich

übermächtig über-ge-schnappt

Unsinn Wahnsinn Menschenwahn

ein Kopf scheint überhoch zu sitzen

auf schlankem Gitterhals

- doch der Kopf ist leer -

und - zum Glück? - bald auch

die Erdöl-Untergrundreserve

alle ungeheuren Wesen

alle menschlichen Konstrukte

fielen einst zusammen

sie werden jetzt auch untergeh'n

- und mit ihnen auch der Mensch? -

mit all dem ungeheuren Übermass

dem Raubbau der Ressourcen

wurde für die Menschen

ganz ungeheuer viel an Leben

zerstört - der ungeheuer gier'ge Mensch

zerstört sich selbst frisst selbst sich auf

doch schauen wir das Bild

vor dem grossen Meer

ist dies Menschenwerk

nichts vor Gottes Werk

zum Glück 